\title{
Active adenosine transporter-mediated adenosine entrance into HL-60 cells leads to the induction of apoptosis through down-regulation of c-Myc
}

\author{
Seong-Hye Hong, ${ }^{1}$ Seong-Yun Jeong, ${ }^{1}$ \\ Sang-Gun Ahn, ${ }^{1}$ In-Sung Hwang ${ }^{1}$ and \\ In-Kyung Kim ${ }^{1,2,3}$ \\ 1 Department of Biochemistry, Catholic University Medical College, \\ Seoul 137-701, Korea \\ 2 Research Institute of Molecular Genetics, \\ Catholic Research Institutes of Medical Science, \\ Catholic University Medical College, Seoul 137-701, Korea \\ 3 Corresponding author. Department of Biochemistry, \\ Catholic University Medical College, 505 Banpo-Dong, \\ Socho-Ku, Seoul 137-701, Korea \\ Accepted 5 September 1997
}

Abbreviations: Ado, adenisine; DPD, dipyridamole; AdoHcy, S-adenosylhomocystine; NBTI, S-(4-nitrobenzyl)-6-thioinosine; DZAri, 3-deazaaristeromycin; DZAHcy, 3deazaadenosylhomocystine; AdoHcyase, AdoHcy hydrolase

\begin{abstract}
Although adenosine (Ado) is being recently recognized as a potent inducer of apoptosis, molecular mechanism of apoptosis by Ado remains to be elucidated. In this study we observed that c-Myc was rapidly down-regulated in the apoptosis in human promyelocytic leukemia HL-60 cells treated with Ado. To establish the molecular and biochemical mechanisms of apoptosis, we tested the specific effects of several antagonists of Ado receptors or inhibitors of Ado transporter on the induction of apoptosis. Treatment of dipyridamole (DPD), an Ado transport inhibitor, effectively suppressed both c-Myc reduction and DNA fragmentation, suggesting that the induction of apoptosis and down-regulation of c-Myc is mediated by active Ado transporter. It was another evidence supporting the entrance of Ado into cells undergoing apoptosis that Ado cytotoxicity was potentiated by a addition of methylation cycle intermediates. These results suggest that the active Ado transportermediated Ado entrance into HL-60 cells leads to the induction of apoptosis through down-regulation of c-Myc.
\end{abstract}

Keywords: adenosine, adenosine transporter, apoptosis, c-Myc, HL-60 cells

\section{Introduction}

Apoptosis, one of physiological modes of cell death, is an endogenous cell suicide mechanism that is selectively triggered in response to various stimuli (Kerr et al., 1972). This is an active, energy-dependent process characterized by stereotypical morphological changes such as cell shrinkage, nuclear condensation, and finally fragmentation of both nucleus and cytoplasm leading to apoptotic bodies (Wadewitz and Lockshin, 1988; Gerchenson and Rotello, 1992). Oncogenes such as c-myc and bcl-2 (Sullivan and Willis, 1989; Hockenbery et al., 1990), tumor suppressor genes including RB and p53 (Benveniste and Cohen, 1995; Szekely et al., 1992), and proteolytic enzymes (Wyllie, 1980; Arends et al., 1990) have been reported to be associated with apoptosis. Among them, c-Myc is one of the most potent mediator for the programmed cell death. However, there are discrepancies in reports showing the relation of apoptosis with the regulation of c-Myc oncoprotein (Onclercq et al., 1989; Bertrand et al., 1991; Evan et al., 1992; Askew et al., 1993; Packham and Cleveland, 1995), implicating cell specificity of regulatory mechanism.

Adenosine (Ado) is known to be an important intracellular molecule acting as an oscillator for circadian rhythm and a ubiquitous neuro-modulator in mammalian central nervous system (Sanchez, 1995; Fredholm et al., 1994). Since cytotoxicity of abnormally accumulated Ado, first observed in adenosine deaminase deficiency disease and severe combined immunodeficiency disease (SCID) (Giblett et al., 1972; Carson and Seegmiller, 1976; Cohen et al., 1978), has been known to lead apoptosis, Ado is recognized as a strong inducer of apoptosis in various normal and tumor cells. Its intracellular increase in such diseases leads an idea that an Ado transporter might play an important role in the entrance of Ado into the cells (Kizaki et al., 1990; Abbrachio et al., 1995). However, several lines of evidence suggest that Ado-induced apoptosis was mediated by Ado specific membrane-bound receptors, like its other functions (Tanaka et al., 1994; Wakade et al., 1994).

We previously reported that apoptosis was induced by Ado in mouse leukemia L1210 cells with a preceding and transient expression of C-Myc (Kim et al., 1994). A human leukemia cell line, HL-60 cells essentially overexpress c-Myc oncoprotein in a basal condition. Thus, the HL-60 cells might be a good model for testing the effects of Ado on apoptosis under c-Myc amplified state.

In this study, we examined the regulation of c-Myc oncoprotein in Ado-treated HL-60 cells as well as the entrance mechanism of Ado into the cells. We have demonstrated here that Ado-induced apoptosis in HL-60 
cells, consequently resulting in rapid down-regulation of c-Myc oncoprotein before appearance of morphological apoptotic features, is mediated by active Ado transporter.

\section{Materials and Methods}

\section{Reagents}

Ado, theophylline, caffeine, dipyridamole (DPD) S-adenosylhomocystine (AdoHcy) were obtained from Sigma Chemical Co. (St. Louis, MO) and S-(4-nitrobenzy1)-6thioinosine (NBTI) was purchased from Research Biochemicals International (Natick, MA). 3-Deazaaristeromycin (DZAri) and 3-deazaadenosylhomocystine (DZAHcy) were donated by Dr. Chiang of the Walter Reed Army Institute of Research, Washington DC. Other reagents not described here were from Sigma Chemical Co. and otherwise specified.

\section{Cell cultures and induction of apoptosis}

Human promyelocytic leukemia HL-60 cells were maintained as a suspension culture in RPMI 1640 medium supplemented with $10 \%$ heat-inactivated $\left(56^{\circ} \mathrm{C}\right.$ for 30 min) fetal bovine serum (FBS) (Hyclone, Logan, UT) and $50 \mu \mathrm{g} / \mathrm{ml}$ of gentamycin, $20 \mathrm{mM}$ HEPES, $25 \mathrm{mM}$ sodium bicarbonate in a humidified atmosphere containing 5\% $(\mathrm{v} / \mathrm{v}) \mathrm{CO}_{2}$ at $37^{\circ} \mathrm{C}$. To examine the effects of Ado in $\mathrm{HL}-60$ cells, cells were plated at a density of $1 \times 10^{6} \mathrm{cells} / \mathrm{ml}$ in 12-well plates and treated with Ado. To study the signalling pathway of Ado-induced apoptosis, Ado receptor inhibitors (theophylline, $100 \mu \mathrm{M}$ ), Ado active transport inhibitor (DPD, $100 \mu \mathrm{M}$ ) or nucleoside uptake inhibitor (NBTI, 100 $\mu \mathrm{M}$ ) were co-treated with Ado or pre-treated for $1 \mathrm{~h}$ before Ado addition. And in the test on methylation cycle intermediates were added at non-toxic doses to Ado-treated cells.

\section{DNA fragmentation analysis}

After treatment, DNA was extracted from HL-60 cells as described (Lee et al., 1995) and $10 \mu \mathrm{g}$ of extracted DNA was electrophoresed in $1.5 \%$ agarose gel. For the quantitative analysis of DNA fragmentation, the amount of intact and fragmented DNA was quantitated by the modified diphenylamine method as described. Cells were lysed with hypotonic lysis buffer (10 mM Tris, $1 \mathrm{mM}$ EDTA, $\mathrm{pH} 7.5)$ containing $0.2 \%$ Triton $\mathrm{X}-100$ and lysates were centrifuged at $13,000 \mathrm{~g}$. Diphenylamine reagents $[0.15 \mathrm{~g}$ diphenylamine (Fisher Scientific, Fairlawn, NJ), $0.15 \mathrm{ml}$ sulfuric acid, $0.05 \mathrm{ml}$ acetaldehyde in $10 \mathrm{ml}$ glacial acetic acid] were added to each tube. After color-development overnight, optical densities were read at $570 \mathrm{~nm}$. The degree of DNA fragmentation was calculated as the percentage of fragmented DNA to total DNA (sum of fragmented DNA and intact DNA).

\section{Examination of cell morphology}

Ado-treated cells were fixed for $1 \mathrm{~h}$ in $4 \mathrm{~F}-1 \mathrm{G}$ fixation solution $\left[\mathrm{NaH}_{2} \mathrm{PO}_{4} \mathrm{H}_{2} \mathrm{O} 11.6 \mathrm{~g}, 50 \%\right.$ (w/v) glutaraldehyde $20 \mathrm{ml}, \mathrm{NaOH} 2.7 \mathrm{~g}, 40 \%$ (v/v) formaldehyde $100 \mathrm{ml}$, made up $1 \mathrm{~L}$ with $\mathrm{H}_{2} \mathrm{O}$ ]. After dehydration cells were embedded in epon resins and sectioned. The ultrathin sections were mounted on nikel grids, stained in a LKB stainer containing uranyl acetate and lead citrate, photographed with a JEM1200 EX (Jeol, Tokyo, Japan) electron microscope at an accelerating voltage of $80 \mathrm{kV}$.

\section{Western blot analysis}

Total cellular proteins prepared from cells lysed in lysis buffer (Laemmli, 1975) were separated by $5-15 \%$ gradient SDS-PAGE and then electroblotted onto a nitrocellulose membrane. After blocking with 5\% non-fat milk in PBS, the membrane was incubated with a mouse monoclonal antibody against human c-Myc protein (Oncogene Science, Cambridge, UK) for $1 \mathrm{~h}$ at room temperature. The blots were washed twice with PBS (room temperature for $15 \mathrm{~min}$ ) and incubated with horseradish peroxidase-conjugated goat anti-mouse immunoglobulin $\mathrm{G}$ as a secondary antibody (Promega, Madison, WI) for $1 \mathrm{~h}$ at room temperature. After washing twice with PBS (room temperature for 15 $\mathrm{min}$ ), the proteins were visualized by enhanced chemiluminescence system (Amersham, Buckinghamshire, UK). The protein bands developed in X-ray film were quantitated by Image Documentation (Stratagene, La Jolla, $\mathrm{CA})$.

\section{Northern blot analysis}

Total RNA from HL-60 cells were extracted with RNAzol $B$ (TEL-TEST, Inc., Friendswood, TX). Equal amount of RNA was separated on a denaturing agarose gel ( $1 \%$ agarose containing 2.2 $\mathrm{M}$ formaldehyde) and then transferred to a nylon filter (Boehringer Mannheim, Mannheim, Germany) by capillary action with $20 \times$ standard saline citrate (SSC). After the filter was UV-crosslinked (UVstratalinker 1800, Stratagene), the filter was prehybridized in high SDS buffer [7\% SDS, $50 \%$ formamide, $5 \times$ SSC, $2 \%$ blocking reagent (Boehringer Mannheim, Mannheim, Germany), $50 \mathrm{mM}$ sodium phosphate $\mathrm{pH} 7.0,0.1 \%(\mathrm{w} / \mathrm{v})$ $\mathrm{N}$-lauroylsarcosine] at $50^{\circ} \mathrm{C}$ for $2 \mathrm{~h}$, and digoxigenin (DIG)labelled human $c$-myc probe prepared from specific primer and cDNA fragment (Amplimer sets, Clontech, Palo Alto, $\mathrm{CA}$ ) by the polymerase chain reaction was added. After hybridization overnight at $50^{\circ} \mathrm{C}$, the nylon membrane was rinsed twice with $2 \times$ SSC, $0.1 \%$ SDS for $5 \mathrm{~min}$ at room temperature, and then sequentially washed twice with 0.1 $\times$ SSC, $0.1 \%$ SDS for $15 \mathrm{~min}$ at $68^{\circ} \mathrm{C}$. DIG-labelled probes were detected by chemiluminescence after treatment with alkaline phosphatase-conjugated antibody against DIG and chemiluminescent substrate, disodium 3-(4-methoxyspiro\{1,2-dioxetane-3,2'-(5'-chloro)tricyclo[3-3.1.1 $\left.1^{3,7}\right]$ decan\}-4-yl)phenylphos-phate (CSPD) (Boehringer 
Mannheim, Mannheim, Germany).

\section{Results}

\section{Adenosine induces apoptosis in HL-60 cells}

To assess the apoptotic effects of Ado in HL-60 cells, DNA was extracted from the cells treated with Ado and then analyzed by agarose gel electrophoresis. As shown in Figure 1B, DNA fragmentation into ladder was observed in the sample treated with $1 \mathrm{mM}$ Ado. This effect of Ado for DNA fragmentation was progressively increased as
A

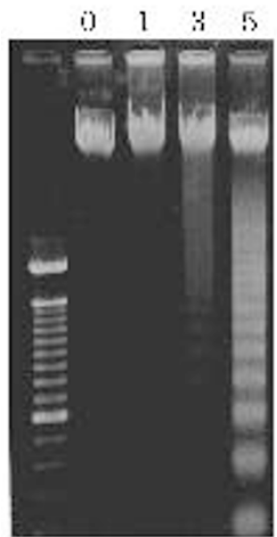

Time ilu?
B

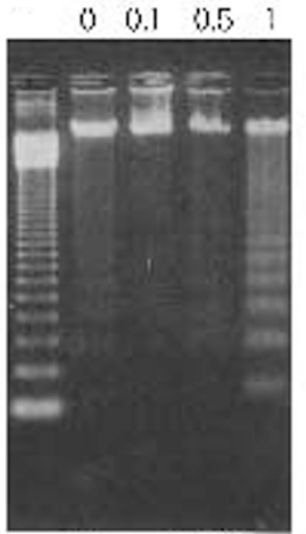

Dnst: (mM)
C

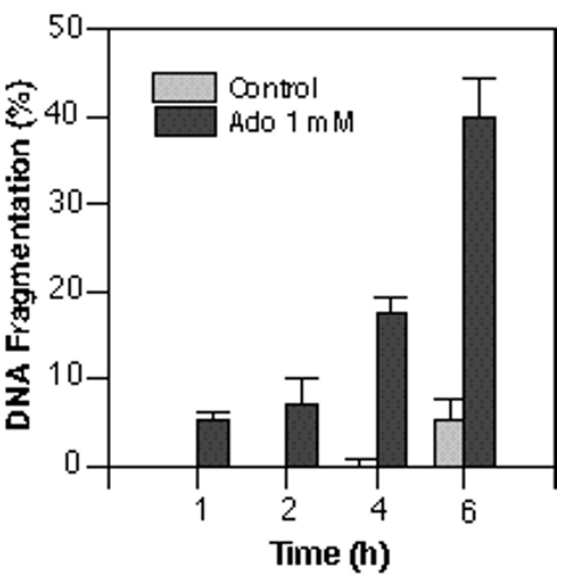

Figure 1. Analysis of DNA fragmentation in HL-60 cells by Ado. Agarose gel electrophoresis of DNA from $\mathrm{HL}-60$ cells treated with 1 $\mathrm{mM}$ Ado for various times $(\mathrm{A})$ and with various concentrations of Ado for $4 \mathrm{~h}$ (B). Lanes 1 shows $123 \mathrm{bp}$ (A) and 100bp (B) DNA size markers, and lane 2 is untreated control, respectively. (C) Timedependent kinetics of DNA fragmentation following $1 \mathrm{mM}$ Ado treatment. Cells $\left(1 \times 10^{6} / \mathrm{ml}\right)$ were treated with Ado for the indicated times was analyzed by diphenylamine method. time dependently as shown in Figure 1A. In these data, we demonstrated that Ado induces DNA fragmentation as a time- and dose-dependent manner, and these findings are supported by previous other reports (Kizaki et al., 1990; Tanaka et al., 1994; Wakade et al., 1994; Abbrachio et al., 1995). The percentages of DNA fragmentation were analyzed by the modified diphenylamine method described in methods. As the time of Ado treatment was increased, the ratio of DNA fragmentation was augmented to $7 \%$ after $2 \mathrm{~h}, 17.5 \%$ after $4 \mathrm{~h}$ and $40.1 \%$ after $6 \mathrm{~h}$ (Figure $1 \mathrm{C}$ ).

To further characterize the morphological effect of Ado on the HL-60 cells, the cells exposed to $100 \mu \mathrm{M}$ of Ado were examined by transmission electron microscopy (Figure 2). Untreated cells showed intact chromatin, cellular organelles and plasma membrane (Figure 2A). After $3 \mathrm{~h}$ of treatment of Ado, we observed the typical apoptosis in early stage showing margination of condensed chromatin and cells are started to become fragmentation in both nucleus and cytoplasm as typical apoptotic bodies (Figure 2B). Apoptotic bodies were mostly shown in cells treated with Ado cells $5 \mathrm{~h}$ (Figure $2 \mathrm{C}$ ).

In these data, we demonstrated that Ado is a very effective and strong inducer of apoptosis in the HL-60 cells. Judging from this time schedule of apoptosis as above, we determined the most appropriate experimental condition
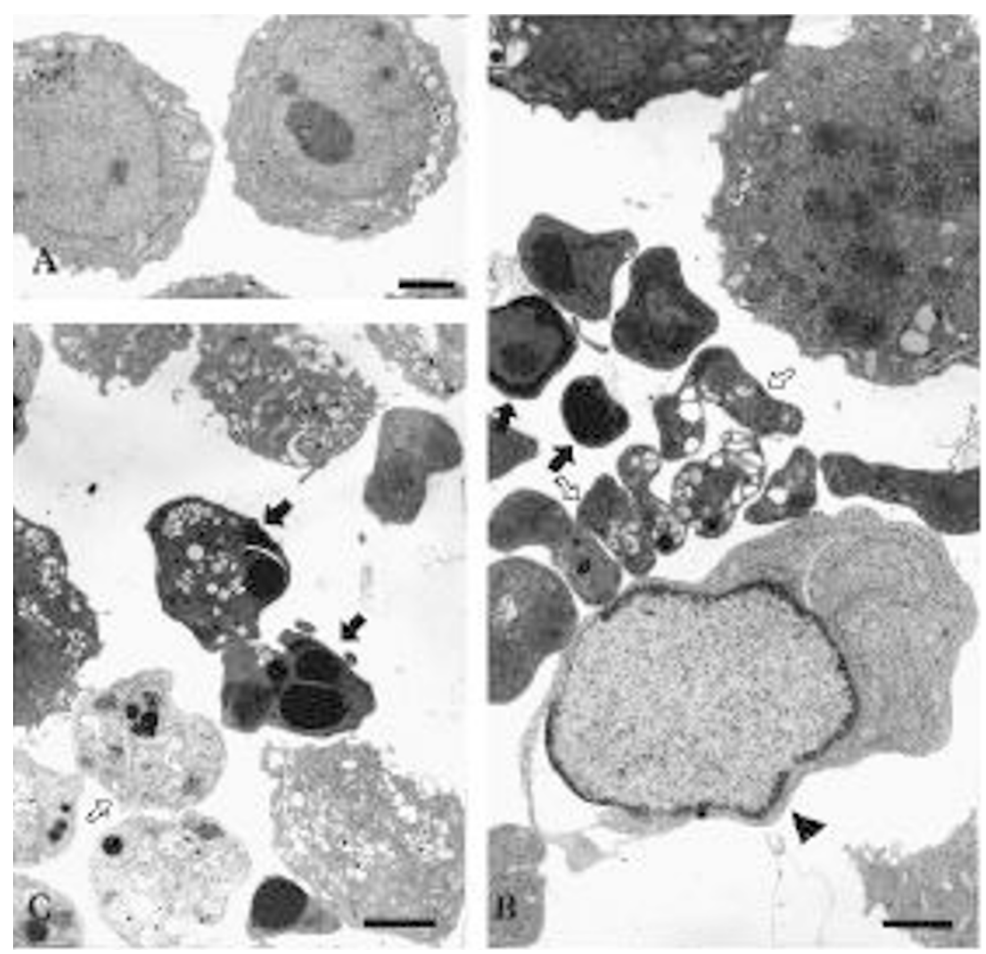

Figure 2. Transmission electron micrographs demonstrating normal $(\mathbf{A} ; \times 4,800)$ and various stages of apoptotic HL-60 cells after treatment with $100 \mu \mathrm{M}$ of Ado for $3 \mathrm{~h}(\mathbf{B} ; \times 4,600)$ or $5 \mathrm{~h}(\mathbf{C} ; \times 4,600)$. Margination of condensed chromatin (arrow head) and apoptotic bodies with (closed arrows) or without (open arrows) nuclear fragments were shown. Bars, $2 \mu \mathrm{m}$. 
for inducing apoptosis as incubation with $1 \mathrm{mM}$ of Ado for at least $3 \mathrm{~h}$, followed by all next experiment in our study.

\section{c-Myc oncoprotein is down-regulated by Ado}

Since Ado-induced apoptosis is associated with change of c-Myc oncoprotein level (Packham and Cleveland, 1995), we tested whether the level of c-Myc oncoprotein is modulated by Ado (Figure 3A). The levels of protein production were determined by Western blot analysis using c-Myc antibody. As the incubation time with Ado was increased, the production of c-Myc 1 and 2 oncoproteins were rapidly reduced as a time-dependent manner. Only $54.5 \%$ of control level remained after 30 min, $22.7 \%$ after $1 \mathrm{~h}$, and undetected levels after $3 \mathrm{~h}$. Next we examined the transcriptional level of c-Myc in Adotreated HL-60 cells. As shown in Figure 3B, the amount of its mRNA was started to decrease after $10 \mathrm{~min}$ of incubation with $1 \mathrm{mM}$ of Ado. While the protein was still detected up to $1 \mathrm{~h}$, the expression of c-myc mRNA was not detected at the same time. This result shows that the level of c-Myc expression is down-regulated at the relatively early stage of apoptosis induced by Ado in $\mathrm{HL}$ 60 cells.

\section{Active Ado transport system mediates apoptosis in $\mathrm{HL}-60$ cells}

Although several groups reported that the induction of apoptosis by Ado in HL-60 cells was mediated by activation

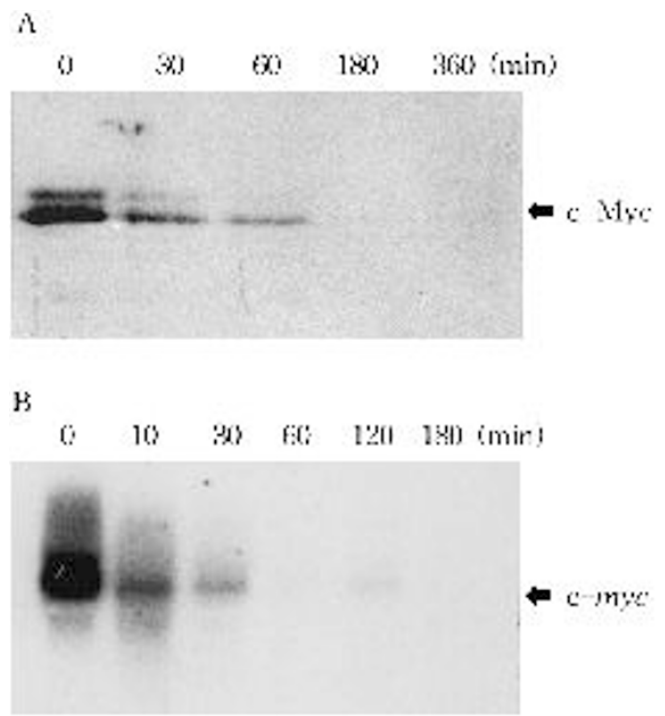

Figure 3. The c-myc expression in Ado-treated HL-60 cells. (A) Immunoblot analysis of c-Myc. Cells $\left(1 \times 10^{6} / \mathrm{ml}\right)$ were treated with $1 \mathrm{mM}$ Ado for indicated times. c-Myc protein was revealed by indirect immuno-peroxidase method using enhanced chemiluminescence detection reagents. (B) Northern blot analysis of the expression of c-myc proto-oncogene in $\mathrm{HL}-60$ cells. After extraction of total RNA from $\mathrm{HL}-60$ cells treated with $1 \mathrm{mM}$ Ado for the indicated times, $25 \mu \mathrm{g}$ of them were loaded. c-myc mRNA was detected using DIG-labeled probe. of membrane-bound Ado receptors (Kizaki et al., 1990; Abbrachio et al., 1995), Ado membrane transporter is known to be responsible for intracellular accumulation of Ado (Thampy and Barnes, 1983), which is the major cause of apoptotic cell death in SCID patients, suggesting that the induction of apoptosis in HL-60 cells may be modulated through Ado membrane transporter. To investigate whether apoptotic cell death occurred in HL-60 cells either by Ado membrane transporter or Ado receptor, we tested the effects of several antagonists of Ado recepter or active Ado transport inhibitors on apoptosis of $\mathrm{HL}-60$ cells treated with Ado. HL-60 cells were treated with $1 \mathrm{mM}$ Ado alone or with Ado and other reagents at $100 \mu \mathrm{M}$. The concentration of reagents used in this study did not show any harmful effects on the proliferation or survival of HL-60 cells (data not shown). Theophyline (Figure 4A) and caffeine (data not shown) known as non-specific Ado receptor antagonists such as $A 1$, and cyclopentylxanthine did not have any effects on DNA fragmentation induced by Ado (data not shown). However, $100 \mu \mathrm{M}$ of DPD, well-known Ado transport inhibitor, or NBTI, a nucleoside uptake inhibitor, effectively suppressed DNA fragmentation caused by treatment of Ado for $3 \mathrm{~h}$ (Figure 4A). The blocking ability was not enough to pertain intact chromatin, but showed satisfactory results in protection from fragmentation into low molecular DNA fragments. When DPD was tested for $1 \mathrm{~h}$ before Ado addition, its inhibitory effect disappeared (lane 7 in Figure 4B). The results shown in Figure 4 indicate that Ado specific transporter acts as a

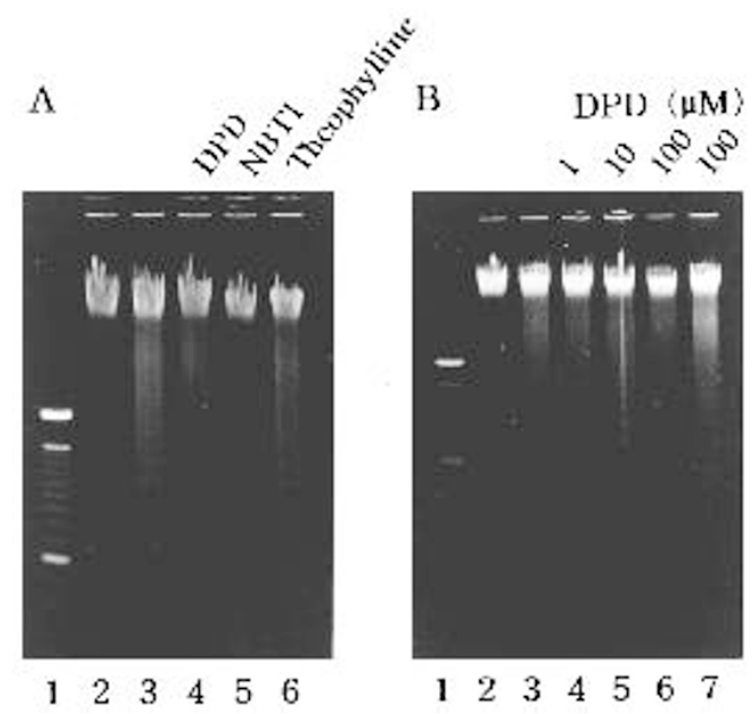

Figure 4. Effects of Ado active transport inhibitors or Ado receptor antagonists. (A) Cells $\left(1 \times 10^{6} / \mathrm{ml}\right)$ were treated with $1 \mathrm{mM}$ Ado alone (lane3) or co-treated with other agents (lane 4-6, $100 \mu \mathrm{M}$ respectively) for $3 \mathrm{~h}$. (B) Ado (1 mM) was treated alone (lane 3), co-treated with DPD for $3 \mathrm{~h}$ (lane 4-6) or treated $1 \mathrm{~h}$ after DPD treatment (lane 7) at indicated concentrations. Lane 1 is 100 bp DNA size markers and lane 2 is untreated control cells, respectively. 

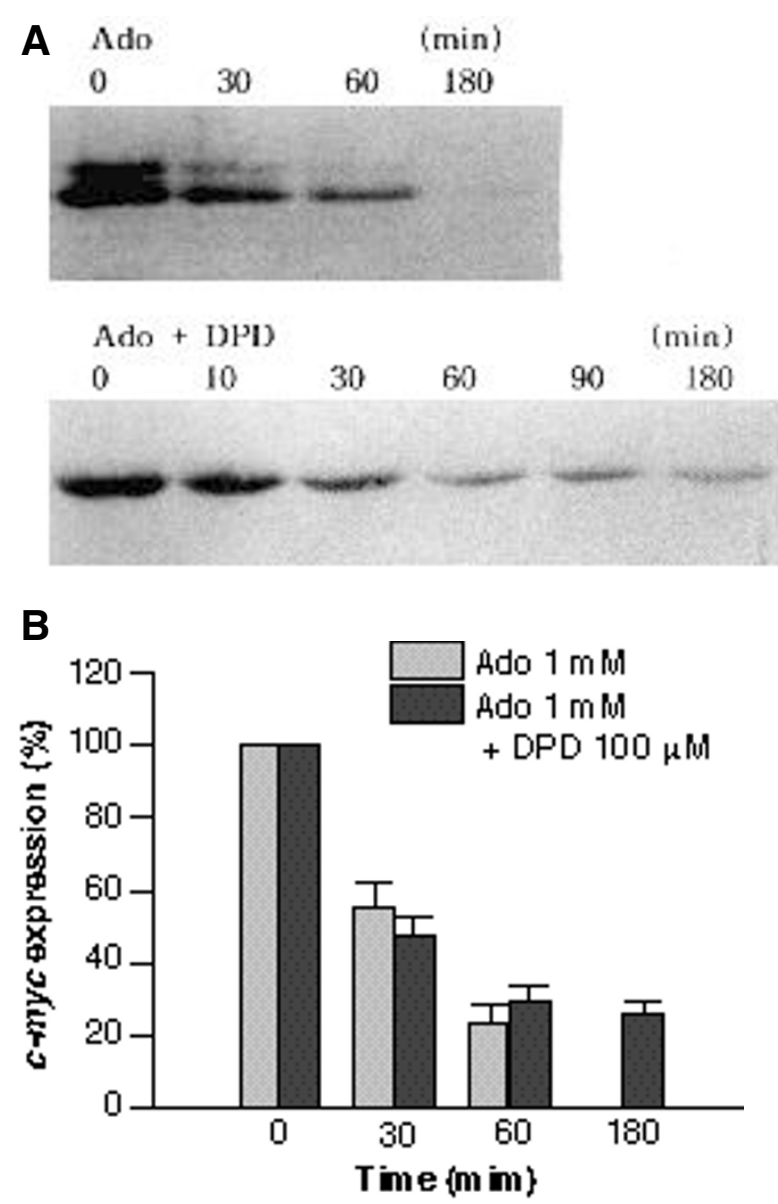

Figure 5. The effect of DPD on the c-Myc expression. After treatment of Ado alone or co-treatment with DPD for indicated times in $\mathrm{HL}-60$ cells $\left(1 \times 10^{6} / \mathrm{ml}\right)$, immunoblot analysis was processed with c-Myc monoclonal antibody. The level of c-myc expression was quantitated using image documentation system.

mediator of Ado uptake into the cells, in contrast to the case of Ado receptor-mediated entrance, resulting in the induction of apoptotic cell death in HL-60 cells. Also, it was reported that from other studies that $A 1$ and $A 2$ Ado receptors do not have a major contribution to apoptosis in HL-60 cells (Tanaka et al., 1994; Kohno et al., 1996).

Our hypothesis inferred from the inhibitory effect of DPD on Ado-induced DNA fragmentation was tested by Western blot analysis of c-Myc oncoprotein after co-treatment of DPD with Ado in HL-60 cells. c-Myc oncoprotein was still expressed as co-treated with DPD at $100 \mu \mathrm{M}$, while the production of c-Myc was not observed in the cells treated with Ado alone for $3 \mathrm{~h}$ (Figure 5). Results shown in both Figure 4 and 5 indicate that the reduction of c-Myc oncoprotein was performed by Ado which is actively transported into the cells. Additionally, incomplete recovery of c-Myc diminution, enough to relieve from the apoptotic cell death in these cells, be caused by incomplete blocking of Ado

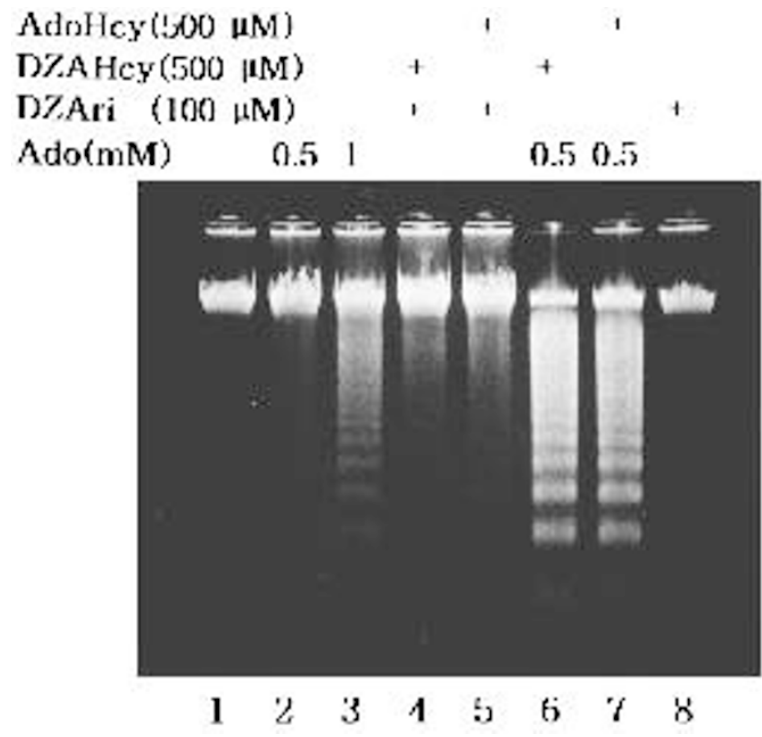

Figure 6. The stimulatory effect of DZAHcy or AdoHcy on Ado-induced apoptosis. HL60 cells $\left(1 \times 10^{6} / \mathrm{ml}\right)$ were treated with Ado alone at the indicated concentrations or cotreated with DZAHcy or AdoHcy of $500 \mu \mathrm{M}$ for $3 \mathrm{~h}$. In the case of DZAri, it was pretreated $3 \mathrm{~h}$ before other agents addition at $100 \mu \mathrm{M}$.

entrance by DPD.

\section{AdoHcy has a synergistic effect on DNA fragmentation by Ado}

It is well illustrated that Ado reacts with L-homocysteine (Hcy) to form AdoHcy by S-adenosylhomocystine hydrolase (AdoHcyase) as the concentration of Ado was increased inside of the cells. The increased concentration of AdoHcy potently inhibits S-adenosyl-L-methioninemediated reactions, which modulate donation of methyl groups to DNA, RNA, and protein (Cantoni et al., 1979), resulting in hypersensitivity of the hypomethylated DNA to nucleases (Lewis and Bird, 1991). Loennechen et al. (1989) reported that methylation cycle was interrupted by DZAri (Lewis and Bird, 1991), a potent inhibitor of AdoHcyase (Kim et al., 1982), DZAHcy, and AdoHcy.

To investigate the effects of methylation intermediates on Ado cytotoxicity in HL-60 cells, we exmined the DNA fragmentation followed by co-treatment of Ado with AdoHcy. In the experiment shown in Figure 6, DNA fragmentation was stimulated at the marginal level when either AdoHcy or DZAHcy was treated with DZAri, a potent inhibitor of AdoHcyase. In cells that Ado was cotreated with AdoHcy or DZAHcy, however, Ado-induced DNA fragmentation was stimulated more than two times that expected if they acted additively. Therefore, these reagents are able to cooperate to produce synergistic stimulation of Ado-induced DNA fragmentation. This observation suggests that the accumulation of AdoHcy 
and DZAHcy leads to inhibit to S-adenosyl L-methionine mediated DNA to nuclease. Therefore, it seems that apoptosis may be due to the combined action with a methylation-dependent manner of DNA.

\section{Discussion}

We have demonstrated that Ado-induced apoptosis in $\mathrm{HL}-$ 60 cells is mediated through an active Ado transporter, consequently resulting in rapid down-regulation of c-Myc oncoprotein before appearance of morphological apoptotic features. The rapid reduction of c-Myc expression in both mRNA and protein level indicates that the production of cMyc oncoprotein is regulated in early step of the apoptotic process in response to Ado surpassing threshold level. Our data show that reduction of c-Myc level lasted for 6 $\mathrm{h}$ describes that apoptosis is a stochastic process, with individual cells committing to the programmed death over an extended time (Packham and Cleveland, 1995). Human promyelocytic leukemia HL-60 cells are tumor cells that constitutively express large amount of c-Myc proteins (Little et al., 1983). It seems that these cells respond to the powerful signals of proliferation which is originated from overexpression of c-Myc and take place as stable tumor cells, perhaps through obtaining circumstance which supplies factors for survival apoptotic suppression, as in the rare reports (Ryan and Birnie, 1996).

Our results that DNA ladder formation was inhibited by DPD, a Ado transporter inhibitor, however, it was not influenced by specific Ado receptor antagonists (Figure $4 \mathrm{~B}$ ) suggest that DNA fragmentation is may be mediated come from membrane-bounded Ado receptors. Also, several lines of evidence in other studies suggested that Ado-induced apoptosis in HL-60 cells was not mediated by Ado-specific A1 or A2 receptor. Tanaka et al. (1994) demonstrated that poly-(ADP-ribosyl)ation, one of early event in apoptosis, was effectively reduced at 100 times lower concentration of DPD than that of Ado ( $10 \mu \mathrm{M}$ versus $1 \mathrm{mM}$ ). However, the concentration of DPD at $10 \mu \mathrm{M}$ was deficient for demoting Ado effect under threshold level and it was necessary for satisfactory result in blocking the formation of DNA ladder at 10 times higher dose. A recent study that Ado cytotoxicity was almost completely protected in neuronal cells when Ado was treated with either Ado-transporter inhibitors such as dilazep or NBTI in the culture indicates that Ado-induced apoptosis may be mediated through an Ado transporter in sympathetic neurons (Wakade et al., 1995). In contrast, Kohno et al. (1996) reported that Ado A3 receptor agonist induced apoptosis in HL-60 cells, which is a membrane- mediated pathway. They were still able to detect $A 3$ receptor mRNA in the absence of Ado A3 receptor agonist. One possible explanation proposes that Ado acts differently from its specific receptor analogs in the induction mechanism of apoptosis, although we presently do not know exact action mechanism of apoptotic pathway.

It is likely that affinity of DPD or NBTI to a transporter is much higher than that of Ado, showing that they effectively inhibited DNA fragmentation even at 10 times lower concentration (100 $\mu \mathrm{M}$ versus $1 \mathrm{mM}$ ) (Figure 4). Cells that were treated with DPD for $1 \mathrm{~h}$ before Ado addition could not neutralize the Ado effect on Ado-induced DNA fragmentation (Figure 4B). The reason for this observation is unclear, but several explanations are possible. First, DPD may be held by Ado transporter and then recycled to plasma membrane. Second, DPD may be rapidly degraded after endocytosis through membrane. Third, DPD has no ability to regulate the programmed cell death like Ado itself. Although DPD gave satisfactory results in blocking DNA fragmentation (Figure 4), it did not provide any meaningful recovery of c-Myc level (Figure 5). From these results, we inferred that blocking of Ado entrance into the cells by DPD was not complete, allowing just weak recovery of cMyc reduction, which, however, protected successfully DNA fragmentation, we describe here that the role of cMyc protein was dependent on the amount of its expression level, not on the presence of the oncoprotein.

Other reports that inhibition of the methylation reaction had an important role in SCID pathogenesis (German et al., 1983) suggest that Ado-induced apoptosis may be correlated with methylation reactions. In this paper, we tested the effect of AdoHcy or DZAHcy to assess the specific mechanism of Ado-induced apoptosis. AdoHcy, which is accumulated due to inhibition of the S-adenosylhomocysteine hydrolase, and DZAHcy, its stable analog, inhibit the activity of methyltransferase (Garcia et al., 1983; Backlund et al., 1986). It was demonstrated that DNA from HL-60 cells exposed to DZA and DZAri, a specific AdoHcy hydrolase inhibitor, was hypomethylated (Loennechen et al., 1989). It is clear that the methylation is known to influence chromatin structures and nonmethylated DNAs have a higher sensitivity to degradation by nucleases than methylated DNAs (Lewis and Bird, 1991). Although DZAHcy or AdoHcy alone did not have any effects on apoptosis of HL-60 cells, consistent with other studies (Endresen et al., 1993; Wakade et al., 1995), synergistic activity of DNA fragmentation between these agents and Ado has potential implications for the regulation of Adoinduced apoptosis of HL-60 cells through perturbance of methylation.

Although c-Myc oncoprotein has important roles in cell cycle progression and transformation, its correlation with apoptosis does not have general agreement owing to specificity in cell types and stimuli. Recent studies demonstrate that reduction of its endogenous level had an obligatory role in the induction of apoptotic cell death regardless of constitutive amount of c-Myc oncoprotein (Packham and Cleveland, 1995). HL-60 cells may loose endogenous c-Myc level in apoptosis. However, stimulation of endogenous c-Myc oncoprotein was also reported to trigger apoptosis in other cell types (Evan et al., 1992; Kim 
et al., 1994). There is no direct evidence that presents requirement of cell cycle progression as c-Myc induces apoptosis and that demonstrates relationship between cMyc and Ado-induced apoptosis (Kimura et al., 1995). The direct evidence for the role of c-Myc in Ado-induced apoptosis of c-Myc amplified HL-60 cells will be supported if apoptosis is inhibited by maintenance of stable expression of c-Myc using potent vehicles in Ado-treated HL-60 cells.

\section{Acknowledgements}

This study was supported in part by a grant from the Mission oriented grant from Korea Science and Engineering Foundation (F015534), the Korea Science and Engineering Foundation through the Cancer Research Center at Seoul National University (KOSEF-SRC-56-CRC94-8) and the 1996 Korean National Cancer Control Program, Ministry of Health and Wellfare, R.O.K. We thank Professor Jin Kim (Department of Anatomy, Catholic University Medical College) for his generous help in the preparation of the electron micrographic experiments. A part of this study will be submitted as In-Sung Hwang's doctoral thesis.

\section{References}

Abbrachio, M. P., Ceruti, S., Barbieri, D., Franceschi, C., Malorni, W., Biondo, L., Burnstock, G. and Cattabeni, F. (1995) A novel action for adenosine: Apoptosis of astroglial cells in rat brain primary cultures. Biochem. Biophys. Res commun. 213: 908-915

Arends, M. J., Morris, R. G. and Wyllie, A. H. (1990) Apoptosis The role of the endonuclease. Am. J. Pathol. 136: 593-608

Askew, D. S., Ihle, J. N. and Cleveland, J. L. (1993) Activation of apoptosis associated with enforced myc expression in myeloid progenitor cells is dominant to the suppression of apoptosis by interleukin-3 or erythropoietin. Blood 82: 2079-2087

Backlund, P. S., Carotti, D. and Cantoni, G. L. (1986) Effects of the S-adenosylhomocysteine hydrolase inhibitors 3-deazaadenosine and 3-deazaaristeromycin on RNA methylation and synthesis. Eur.J. Biochem. 160: 245-251

Benveniste, P. and Cohen, A. (1995) p53 expression is required for thymocyte apoptosis induced by adenosine deaminase deficiency. Proc. Natl. Acad. Sci. USA 92 8373-8377

Bertrand, R., Sarang, M., Jenkin, J., Kerrigan, D. and Pommier, Y. (1991) Differential induction of secondary DNA fragmentation by topoisomerase II inhibitors in human tumor cell lines with amplified c-myc expression. Cancer Res. 51: 6280- 8285

Cantoni, G. L., Richards, H. H. and Chiang, P. K. (1979) In Transmethyl-ation (Usdin, E., Borchardt, R. T. and Croseling, E. R. eds.) pp. 155-164, Elsevier, Amsterdam, New York

Carson, D. A. and Seegmiller, J. E. (1976) Effect of adenosine deaminase inhibition upon human lymphocyte blastogenesis. J. Clin. Invest. 57: 274-282

Cohen, A., Hirschhorn, R., Horowitz, S. D., Rubinstein, A., Polmar, S. H., Hong, R. and Martin, D. W. (1978) Deoxyadenosine triphosphate as a potentially toxic metabolite in adenosine deaminase deficiency. Proc. Natl. Acad. Sci. USA 75: 472-476

Endresen, P. C., Eide, T. J. and Aarbakke, J. (1993) Cell death initiated by 3 deazaadenosine in $\mathrm{HL}-60$ cells is apoptosis and is partially inhibited by homocysteine. Biochem. Pharmacol. 46: 1893-1901

Evan, G. I., Wyllie, A. H. Gilbest, C. S., Littlewood, T. D., Land, H., Brooks, M., Waters, C.
M., Penn, L. Z. and Hancock, D. C. (1992) Induction of apoptosis in fibroblasts by c-myc protein. Cell 69: 119-128

Fredholm, B. B., Abbracchio, M. P., Burnstock, G., Daly, J. W., Harden, T. K., Jacobson, K. A., Leff, P. and Williams, M. (1994) Nomenclature and classification of purinoceptors. Parmacol. Rev. 46: 143-156

Garcia-Castro, I., Mato,M. J., Vasanthakumar, G., Wiesmann, W. P., Schiffmann, E. and Chiang, P. K. (1983) Paradoxical effects of adenosine on neutrophil chemotaxis. J. Biol. Chem. 258:4345-4349

German, D. C., Bloch, C. A. and Kredich, N. M. (1983) Measurements of Sadenosylmethionine and L-homocysteine metabolism in cultured human lymphoid cells. J. Biol. Chem. 258: 10997-11003

Gerschenson, L. E. and Rotello, R. J. (1992) Apoptosis: A different type of cell death. FASEB J. 6: 2450-2455

Giblett, E. R., Anderson, J. E., Pollara, B. and Meuwissen, H. J. (1972) Adenosinedeaminase deficiecy in two patients with severely impaired cellular immunity. Lancet 2: 1067-1069

Guranowski, A., Montgomery, J. A., Cantoni, G. L. and Chiang, P. K. (1981) Adenosine analogues as substrates and inhibitors of S-adenosylhomo-cysteine hydrolase. Biochemistry 20: 110-115

Hockenbery, D., Nunez, G., Milliman, C., Schreiber, R. D. and Korsmeyer, S. J. (1990) $\mathrm{BCl}-2$ is an inner mitochondrial membrane protein that blocks programmed cell death. Nature 348, 334-336

Kerr, J. F. R., Wyllie, A. H. and Currie, A. R. (1972) Apoptosis: A basic biological phenomenon with wide-ranging implications in tissue kinetics. Br.J. Cancer 26: 239-257

Kim, I. K., Aksamit, R. R. and Cantoni, G. L. (1982) Mechanism of the cytostatic activity of 3-deazaaristeromycin, an inhibitor of adenosylhomo-cysteine hydrolase. J. Biol. Chem. 257: 14726-14729

Kim, I. K., Copeland, R. L. Jr., Lee, J. H., Kim, H. S., Asafo-Adjei, Brown, N. D., Estrada, J. S., Gordon, R. K., Garcia, G. E. and Chiang, P. K. (1994) Induction of apoptosis and cmyc in L1210 lymphocytic leukemia cells by adenosine. J. Biomed. Sci. 1: 154-157

Kimura, S., Maekawa, T., Hirakawa, K., Murakami, A. and Abe, T. (1995) Alterations of c-myc expression by antisense oligodeoxynucleotides enhance the induction of apoptosis in HL-60 cells Cancer Res. 55: 1379-1384

Kizaki, H., Suzuki, K., Tadakuma, T. and Ishimura, Y. (1990) Adenosine receptormediated accumulation of cyclic AMP-induced T-lymphocyte death through internucleosomal DNA cleavage. J. Biol. Chem. 265: 5280-5284

Kohno, Y., Sei, Y., Koshiba, M., Kim, H. O. and Jacobson, K. A. (1996) Induction of apoptosis in $\mathrm{HL}-60$ human promyelocytic leukemia cells by adenosine $A_{3}$ receptor agonists. Biochem. Biophys. Res. Commun. 219: 904-910

Laemmli, U.K. (1975) Characterization of DNA condensates induced by poly(ethyleneoxide) and polylysine. Proc. Natl. Acad. Sci. USA72: 4288-4292

Lee, J. H., Kim, H. S., Jeong, S. Y. and Kim, I. K. (1995) Induction of p53 and apoptosis by $\Delta^{12}-\mathrm{PGJ} \mathrm{J}_{2}$ in human hepatocarcinoma SK-HEP-1 cells. FEBS. Lett. 368: 348-352

Lewis, J. and Bird, A.(1991) DNA methylation and chromatin structure. FEBS. Lett. 285: 155-159

Little, C. D., Nau, M. M., Carney, D. N., Gazdar, A.F. and Minna, J. D. (1983) Amplification and expression of the c-myc oncogene in human lung cancer cell lines. Nature 306: 194-196

Loennechen, T., Prytz, P. S. and Aarbakke, J. (1989) DNA-methylation in HL-60 cells treated with 3-deaza-( \pm -aristeromycin and 3-deazaadenosine. Biochem. Pharmacol. 38: 2748-2751

Onclercq, R., Barbinet, C. and Cremisi, C. (1989) Exogenous C-Myc gene overexpression interferes with early events in F9 cell differentiation. Oncogene Res. 4: 293-302 
Packham, G. and Cleveland, J. L. (1995) c-Myc and apoptosis. Biochim. Biophys. Acta 1242: $11-28$

Ryan, K. M. and Birnie, G. D. (1996) Myc oncogenes: the enigmatic family. Biochem. J. 314: 713-721

Sanchez, V. C. (1995) Circadian variations of adenosine and of its meta-bolism. Could adenosine oscilator for circadian rhythms? Can. J. Physiol. Pharmacol. 73: 339-355

Sellins, K. S. and Cohen, J. J. (1987) Gene induction by $\gamma$-irradiation leads to DNA fragmentation in lymphocytes. J. Immunol. 139: 3199-3206

Sullivan, N. F. and Willis, A. E. (1989) Elevation of c-myc protein by DNA strand breakage. Oncogene 4: 1497-1502

Szekely, L. W., Jiang, Q., Bulie-Jakub, F., Rosen, A., Ringerts, N., Klein, G. and Wimman, K. C. (1992) Cell type and differentiation dependent heterogeneity in retinoblastoma protein expression in SCID mouse fetuses. Cell Growth Differ. 3: 139-156

Tanaka, Y., Yoshihara, K., Tsuyuki, M. and Kamiya, T. (1994) Apoptosis induced by adenosine in human leukemia HL-60 cells. Exp. Cell Res. 213: 242-252

Thampy, K. G. and Barnes, E. M. Jr. (1983) Adenosine transport by primary cultures of neurons from chick embryo brain. J. Neurochem. 40: 874-879

Wadewitz, A. G. and Lockshin, R. A. (1988) Programmed cell death: Dying cells synthesize a co-ordinated, unique set of proteins in two different episodes of cell death. FEBS Lett. 241: 19-23

Wakade, T. D., Palmer, K. C, MeCauley, R., Przywara, D. A. and Wakade, A. R. (1995)
Adenosine-induced apoptosis in chick embryonic sympa-thetic neurons: A new physiological role for adenosine. J. physiol. 488: 123-138

Wyllie, A. H. (1980) Glucocorticoid-induced thymocyte apoptosis is associated with endogenous endonuclease activation. Nature 284: 555-556 